\title{
THE DESIGN OF A MORE SUSTAINABLE TRAVELLING EXHIBITION
}

\author{
Anna BIEDERMANN, José Luis SANTOLAYA SÁENZ, Natalia MUÑOZ LÓPEZ and Ana \\ LÓPEZ CANELLAS \\ Universidad de Zaragoza, Spain
}

\begin{abstract}
Design and engineering education requires continuous adaptation to the existing environmental and social challenges. The design of sustainable and socio-ethical new solutions that involve not only the design of industrial products but also services and systems that combine products and services is currently considered in several studies as a satisfactory way to work.

This study shows how practical methods considering sustainability principles are applied to design a more sustainable cultural service. A project dedicated to the development of a travelling exhibition is addressed. Sustainability has been evaluated using the Life Cycle Sustainability Assessment (LCSA) method that takes into account the environmental, economic, and social dimensions. A set of sustainability indicators have been used and impacts associated with each dimension have been obtained in the three main stages established within the service life cycle: implementation, operation, and dismantling. Factors that cause the highest impact have been identified and design alternatives to improve the sustainability of the service have been proposed. To prove if the new service design generates less impact, a comparison between sustainability indicators of both initial and new service has been conducted.

Promoting the improvement of sustainability in design projects is increasingly required. This kind of final degree project underlines the responsibility the designers have to be aware of the impacts of their designs as well as allows the students to gain experience in an area in which they can practice the profession.
\end{abstract}

Keywords: Sustainable design, cultural service, design methods

\section{INTRODUCTION}

The cultural sector represents many employment opportunities for the designers and the concern about sustainability in this sector is growing. In the last decades, notable efforts have been observed in museums and institutional buildings, in which transformations towards reducing its environmental impacts, especially the energy demand $[1,2]$ have been performed. Initiatives as Leadership in Energy and Environmental Design in the USA [3] had helped to establish criteria for building environment improvement. The environmental and human health impacts have been also addressed in a study of exhibitions at the Museum of Fine Art in Boston [4].

On the other hand, Life Cycle Assessment (LCA), standardized in ISO 14040 [5], is already applied to multiple products and processes across a wide range of sectors. LCA requires databases that define the impacts of each material, product, and service. Nunberg et al., [6] are developing one dedicated to cultural heritage preservation and exhibition practices. The above-mentioned research is a pioneer in LCA application to the museum's permanent exhibited objects. Museums use also temporary exhibitions to engage with the public, make local audiences' return to the museum, and help to attract sponsors and media attention [7] and maintain ticket pricing [8].

In the context of Higher Education, a movement to adopt the Sustainable Development Goals (SDG) [9] and sustainability can be observed. The Association of University Leaders for a Sustainable Future [10] and the Association for the Advancement of Sustainability in Higher Education [11] were created to encourage a commitment to teaching and research in sustainability. Multiple declarations to introduce sustainability in the agenda of higher education institutions have been published [12].

The Final Degree Projects (FDP) represent a great opportunity to the students to apply knowledge in an interdisciplinary field, introducing new methods and techniques that can respond to the constantly 
evolving environmental and social situation. In the case of a Bachelor's Degree in Industrial Design and Product Development Engineering at the University of Zaragoza, students have the option to enrol in the elective course focused on SDG, but it does not equip them with practical tools for addressing the evaluation and improvement of the system's sustainability. A group of professors teaching in this degree decided to offer FDP that include sustainability assessment. Those tutors are researchers in the field of sustainability and cultural service design and offer to the students the tools considered most adequate for the scope of the projects. FDPs are realized by students individually and are tutorized or co-tutorized by chosen professors during approximately 5 months in weekly sessions. The FDP corresponds to 12 ECTS, the object is chosen by both student and teacher and it is approved by the degree academic commission that checks if the object and scope of work are adequate.

In this work, FDP focused on temporary travelling exhibitions is presented. The sustainability of this system has been analysed, based on a real case with authentic inventory and improvement options have been explored theoretically. In particular, a new design of the exhibition area has been projected. The sustainability of the initial and new designs has been, finally, compared. The presented case study aims to respond to the following research question: Can FDP be treated as a try for new content implementation to Engineering Industrial Design Degree, with the special focus on LCSA methods applied to the cultural sector?

\section{METHODOLOGY}

In order to achieve more sustainable systems (products or services) taking into account a life cycle perspective, a methodology organized in three main phases is applied in this work (Figure 1):

Phase 1 - The sustainability of the initial design is assessed according to the Life Cycle Sustainability Assessment (LCSA) [13] approach. Environmental impacts, economic aspects and social issues are evaluated by compiling inputs and outputs of the system object of study and using a set of suitable indicators. The impact spots are detected.

Phase 2 - A more sustainable design is projected taking into account sustainability results obtained in the previous phase and without compromising specifications already established in the initial system. Several sustainability strategies can be proposed. A new inventory should be performed to obtain the sustainability indicators of the new design.

Phase 3 - Comparing designs. The sustainability of both initial design and redesign is compared to detect if improvements have been achieved. The parallel presentation of individual indicators as well as the use of an aggregated sustainability index to obtain a global evaluation can be carried out.

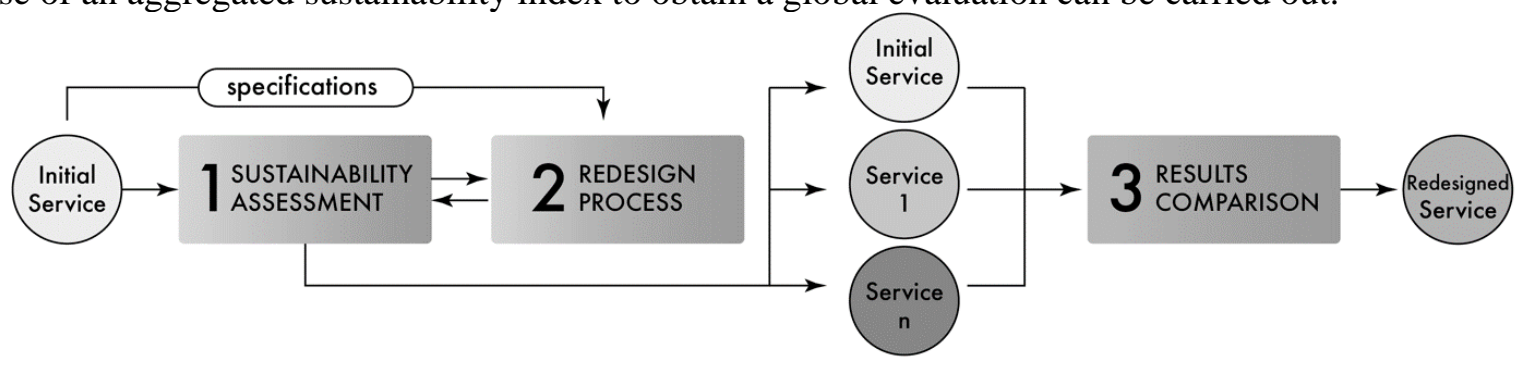

Figure 1. Phases of a redesign of more sustainable services

Different indicators are proposed in this work to quantitatively assess each of the three sustainability dimensions. The Global Warming Potential $\left(\mathrm{GWP}_{100}\right)$, which represents total emissions of the greenhouse gases calculating the radiative forcing over a time horizon of 100 years, is the environmental indicator selected. The Execution Cost $\left(\mathrm{C}_{\mathrm{E}}\right)$ or total cost to develop an activity is used in the economic dimension and the average Working Time $\left(\mathrm{T}_{\mathrm{W}}\right)$ is the indicator selected to value the social impact (the category of workers is selected according to UNEP's guidelines [14]).

Complementary tools were used to obtain these indicators: the Cype Software that provides data of costs and working times in construction, assembly/disassembly and transport activities; the CE3X local software, which is used to estimate energy consumptions due to air conditioning in buildings taking into account both geographic location data and constructive features; emission factors of electric commercial companies [15] were applied to evaluate greenhouse gas emissions from electric consumptions; finally, data of greenhouse gas emissions of a number of materials used in the creation of the exhibition area were obtained through the Gabi software. 


\section{CASE STUDY - ITINERARY EXHIBITION}

Methodology was applied to improve the sustainability of a temporary travelling exhibition, in which historical contents are exhibited. After its inauguration in Madrid, the exhibition will travel to seven different European destinations. The service lifecycle has been divided into creation, provision, and end of life stages (Figure 2) and detailed inventory has been carried out using primary data collected during the creation, provision, and end of life stages of the exhibition in the first destination.
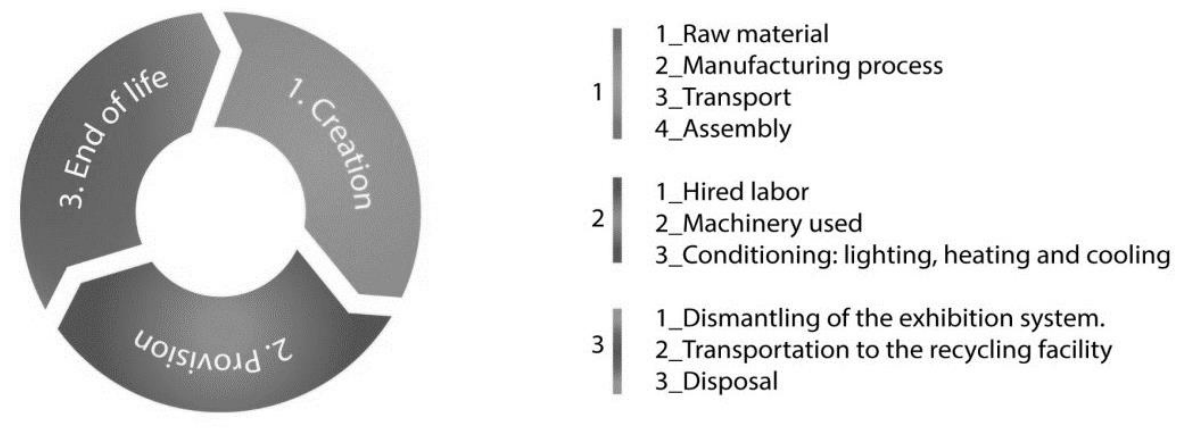

Figure 2. Life cycle stages and research scope

The exhibition is open every day for 11 hours for 6 months. Activities of ticketing, public attention, coordination, gift shop and cloakroom are developed in two shifts of $5.5 \mathrm{~h}$ each day. The security of the exhibition is organized in three shifts of $8 \mathrm{~h}$ ( 3 workers in each one) and cleaning activities (including daily vacuuming of the carpet) are carried out before opening in one shift of $3 \mathrm{~h}$. Suitable lighting, heating, and cooling conditions (for the exhibits and visitors) are created in the exhibition. $205 \mathrm{MWh}$ were consumed by heating, $24 \mathrm{MWh}$ by refrigeration and $76 \mathrm{MWh}$ by primary lightning. A total number of 300,385 visits were registered during 6 months in the first destination of the exhibition. Each visitor spent on average $3.25 \mathrm{~h}$ and an elevated number of visitors (70\%) used an audio guide system. The recharge of audio guides supposed a consumption of $14.3 \mathrm{MWh}$.

The preliminary conditioning of the exhibition area involves the construction of a modular walls system with the printed material displayed on them (printed and cut-out vinyl) as well as covering the floor with a polyamide carpet. A total of 415 modules of $1 \times 3 \times 0.2 \mathrm{~m}$ each one, are conveniently distributed in the exhibition area. The structure is made of wood slats, joined by dowels and adhesives, and later covered with medium-density fibreboard (MDF) panels (Figure 3). Printed vinyl $\left(372.87 \mathrm{~m}^{2}\right)$ and cut-out vinyl $\left(83.73 \mathrm{~m}^{2}\right)$ are attached in some of these modules. A polyamide carpet thickness $6 \mathrm{~mm}$, fixed with a flooring adhesive, is used to cover the floor in the exhibition hall. To prevent damage during modules assembly and painting processes, the carpet includes a plastic protector, which is removed before the exhibition opening.
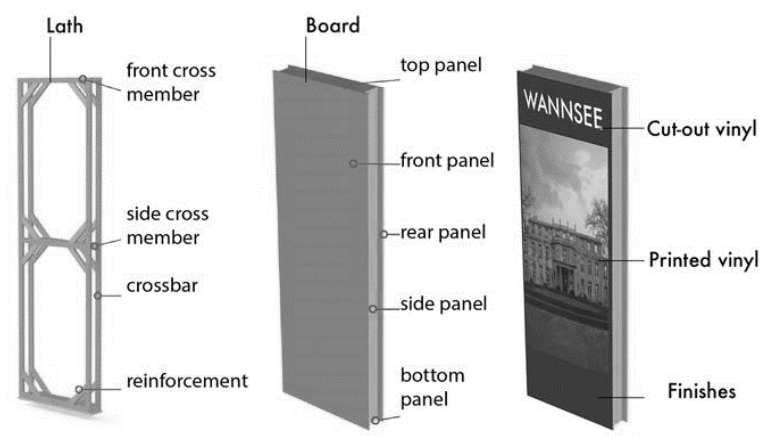

\begin{tabular}{|c|c|c|}
\hline \multicolumn{3}{|l|}{ Raw material $\left(\mathrm{BS}_{1}\right)$} \\
\hline Element & Unit & \\
\hline Lath $(30 \times 50 \times 3000 \mathrm{~mm})$ & $2,947.00$ & pcs. \\
\hline Board $(19 \times 2100 \times 3660 \mathrm{~mm})$ & 479.00 & pcs. \\
\hline Dowels $(\varnothing 10 \times 30 \mathrm{~mm})$ & $23,240.00$ & pcs. \\
\hline Lag screws ( $\varnothing 3,5$ × 35 mm) & $35,654.00$ & pcs. \\
\hline Printed vinyl & 372.87 & $\mathrm{~m} 2$ \\
\hline Cut-out vinyl & 83.73 & $\mathrm{~m} 2$ \\
\hline Transfer Paper & 83.73 & $\mathrm{~m} 2$ \\
\hline Ink & 5.18 & 1 \\
\hline Adhesive & 4.47 & kg \\
\hline Finishes & $2,490.00$ & $\mathrm{~m} 2$ \\
\hline
\end{tabular}

Figure 3. Temporary wall structure and raw materials inventory used in the original service

The manufacturing process, transport to the exhibition hall and assembly on site of the modular walls system was examined. The sequence of activities performed by the team of carpenters as well as the materials required to the full preparation of the exhibition area, were determined [16]. In each destination, dismantling activities after the exhibition was closed, were also analysed. Exhibition display panels are not reused, so that these are classified into appropriate categories and transported to waste 
management plants. On the other hand, the transport of artifacts (historical objects and art pieces), showcases, wall cases and frameworks as well as reproductions, facsimiles, models etc. between different destinations is carried out through 110 flying cases and 3 trucks. A total volume of $172.55 \mathrm{~m}^{3}$ and a total weight of $19,600 \mathrm{~kg}$ are transported an average distance of $578.14 \mathrm{~km}$. To limit the complexity of the study, the creation process of the artifacts, showcases and audio-visual content of the exhibition are not included within this research.

The quantitative measure of the impacts in each sustainability dimension was carried out using the indicators previously defined. Results are summarized in Table 1 . The creation stage has an important impact. It includes raw materials, manufacturing processes, transport, and assembly. The raw materials used in the preliminary conditioning of the exhibition area accounts for $61.7 \%$ of the total service greenhouse gas emissions. Costs due to the use of raw materials in the previous preparation of the exhibition space are also relatively important $(23.8 \%)$. In consequence, this is a very significant factor affecting the sustainability of the system.

In the second phase, improvement strategies are applied taking into account initial specifications of the system. Particularly, the itinerary exhibition requires that the assembly/disassembly activities could be easily carried out in each destination. It is also necessary to keep specific aesthetics giving an illusion of continuity in the exhibition space, to ensure appropriate attention to visitors, and to guarantee the security of the contents exhibited. The sustainability results obtained reveal a significant impact factor of the raw materials used in the preliminary assembly of the exhibition area- materials used for walls, carpet and display supports. These materials are discarded after the exhibition finishes at each destination so that a new modular walls system (415 modules) and a new carpet (around 2,500 $\mathrm{m}^{2}$ ) have to be manufactured in each location. Thus, the use of a new modular walls system that could be transported and reused in different locations is proposed as a sustainability strategy. The new modular walls system consists of standard anodized aluminium profiles assembled with quick joints and covered with two panels made of polyester fabric with a silicone guide in its contour (Figure 4). The fabric will be printed so there will be no need to attach vinyl on it. Since the walls will not be painted and assembly will be done dry, a $3 \mathrm{~mm}$ thick carpet made of polyester without a protector is proposed to cover the technical floor. The carpet is fixed with flooring adhesive.
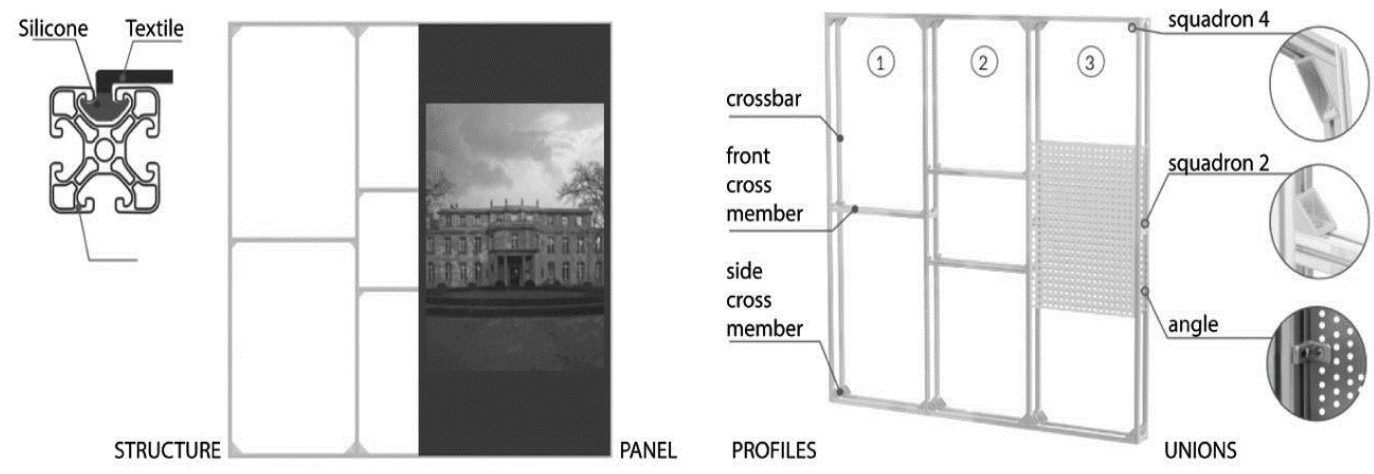

Figure 4. Temporary wall structure used in the redesigned service

Applying this strategy, only the carpet (which has to be replaced in its totality), and textile panels containing text (10\% have to be replaced because of the language change) are newly manufactured in the second and subsequent locations where the exhibition is open. The total replacement of carpet is needed as the fair carpet is being used and after the intensive exploitation - more than 300.000 visitors in one destination it does not maintain the aesthetic and other characteristics needed for the new opening. Most of the elements used in the exhibition conditioning can be reused. The total volume of materials, which is required throughout 8 destinations, is greatly reduced from 793.3 to $99.1 \mathrm{~m}^{3}$. Materials can be transported in 2 trucks, which are included in the transport service.

As all destinations are within Europe and transport has a limited impact on the whole system $(1.5 \%$ in the case of $\mathrm{GWP}_{100}, 0.4 \%$ in $\mathrm{C}_{\mathrm{E}}$ and $\mathrm{T}_{\mathrm{W}}$ indicators) the same transport model has been applied in the redesigned proposal. Finally, the third phase of methodology is carried out, and the comparison between indicators of original and redesigned is conducted (Table 1). 
Table 1. Sustainability indicators of original - redesigned service (data expressed per visit)

\begin{tabular}{ccccccc} 
& \multicolumn{2}{c}{$\mathrm{GWP}_{100}\left(\mathrm{~kg} \mathrm{CO}_{2}\right)$} & \multicolumn{2}{c}{$\mathrm{C}_{\mathrm{E}}(€)$} & \multicolumn{2}{c}{$\mathrm{T}_{\mathrm{W}}(\mathrm{h})$} \\
\hline & Original & Redesigned & Original & Redesigned & Original & Redesigned \\
\hline CREATION & 0.39 & 0.05 & 0.55 & 0.23 & 0.0023 & 0.0011 \\
PROVISION & 0.22 & 0.22 & 1.20 & 1.2 & 0.0032 & 0.0032 \\
END OF LIFE & 0.0013 & 0.0003 & 0.04 & 0.02 & 0.0005 & 0.0007 \\
\hline TOTAL & 0.61 & 0.27 & 1.78 & 1.44 & 0.0060 & 0.0049 \\
\hline
\end{tabular}

Figure 5 shows a comparison between the environmental, economic, and social indicators of original accommodation and its redesign. The applied strategy resulted in the impact reduction registered in all dimensions. Taking into consideration the redesigned service its impact has been reduced by $55.21 \%$, $19.13 \%$ and $18.2 \%$ respectively, calculated in $\mathrm{GWP}_{100}, \mathrm{C}_{\mathrm{E}}$ and $\mathrm{T}_{\mathrm{W}}$ indicators compared to the original service. The major reductions take place in the creation stage; in the environmental dimension the $\mathrm{GWP}_{100}$ indicator has been reduced by $86.53 \%$ of its original value, in the economic dimension the cost has been reduced by $58.83 \%$, and in the social dimension the working time is reduced by $53.64 \%$. The provision stage impacts have not changed as no modification in this part of the life cycle of the service has been applied in order to provide the unchanged visiting experience to the public. In the end of life stage, the impact has been reduced by $76.41 \%$ and $50.28 \%$ respectively, calculated in $\mathrm{GWP}_{100}$ and $\mathrm{C}_{\mathrm{E}}$ indicators compared to the original service, however in $\mathrm{T}_{\mathrm{W}}$ indicator the value has increased $30.14 \%$ as the disassembly is more time demanded in the redesigned system. Nonetheless, the impacts of the end of life stage in the whole life cycle are not of great importance: it represents $0.2 \%$ of the whole system in the case of the original design, and $0.05 \%$ in the case of the redesigned system. The transport of the modular system between different destinations has no significant impact.
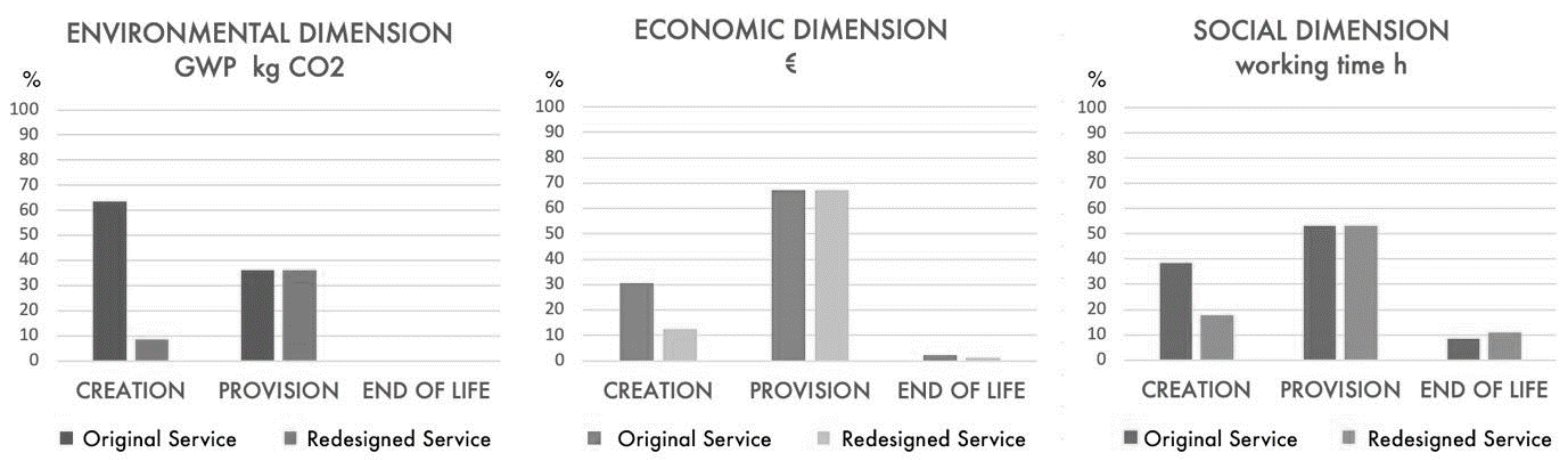

Figure 5. Comparing indicators of original- redesigned service

The overall improvement in the sustainability of the system can be determined by applying different weights to each dimension. 4 possibilities have been considered and results have been collected in Table 2. In all cases, the results are positive, which indicates favourable results.

Table 2. Sensitivity analysis to the weighting of the sustainability indicators

\begin{tabular}{|c|c|c|c|c|c|}
\hline & & C1 & $\mathrm{C} 2$ & C3 & C4 \\
\hline Indicator & Variation (\%) & \multicolumn{4}{|c|}{ Coefficient } \\
\hline GWP 100 & 55.21 & 0.33 & 0.50 & 0.25 & 0.25 \\
\hline Costs & 19.13 & 0.33 & 0.25 & 0.50 & 0.25 \\
\hline \multirow[t]{3}{*}{ Working time } & 18.20 & 0.33 & 0.25 & 0.25 & 0.50 \\
\hline & & \multicolumn{4}{|c|}{ Sustainability improvement } \\
\hline & & 30.85 & 36.94 & 27.92 & 27.69 \\
\hline
\end{tabular}

\section{CONCLUSIONS}

The sustainability of a temporary travelling exhibition has been assessed applying LCSA methodology and a more sustainable option has been proposed. The originally used modular system of wood and MDF walls has been replaced in each destination of the exhibition. It has been compared with a 
redesigned exhibition system made of aluminium and textile that could travel and be reused in all destinations. Also, the carpet material has been modified to lower the environmental impacts. The results show a decrease in the indicators in the redesigned system across eight European destinations. As the number of destinations increases, the profitability improves, and emissions decrease comparing both systems; being the environmental dimension the most influenced. The main factor of influence is the raw material reusing.

The introduction of sustainability assessment in FDP was interesting for the students, who had the opportunity to prove their competencies in design activities while acquiring LCSA knowledge and have their first experiences in the cultural service design. The presented project has been defended in front of the members of the FDP commission and has been assessed with a score of 9 out of 10 , which is a very positive academic result. The student feedback was positive, highlighting the fact that the sustainability assessment gives a new perspective in the design and redesign process, because of the consciousness of the sustainability impacts of design choices. The FDP resulted in an opportunity for the teachers to include new content to the students which otherwise would require a modification of the study program which is an administrative and time costing procedure. The FDP can be therefore perceived as a field of exploitation of new topics that in the future can be used for adaptation of teaching curricula. Student's feedback is vital and valuable, especially that they have reached certain professional maturity and can assess the value of new contents from the whole degree perspective.

\section{REFERENCES}

[1] Sutton S. Environmental Sustainability at Historic Sites and Museums. Rowman \& Littlefield, 2015.

[2] Brophy S. S. and Wylie E. The green museum: A primer on environmental practice. Altamira Press, 2013.

[3] U.S. Green Building Council https://www.usgbc.org/leed [Accessed on 2020, 23 September].

[4] Nunberg S., Eckelman M. and Hatchfield P. Life cycle assessments of loans and exhibitions: three case studies at the Museum of Fine Arts, Boston. J Am Inst Conserv, 2016, 55(1):2-11

[5] ISO 14044:2006 - Environmental management life cycle assessment - requirements and guidelines. International Organization for Standardization, 2006.

[6] Nunberg S., Sutton S. and Eckelman M. Planning a Life Cycle Analysis Library and Beta Tool for Sustainable Cultural Heritage Preservation and Exhibition Practices. In Addressing the Challenges in Communicating Climate Change Across Various Audiences, 2019. pp. 531-543. Springer, Cham.

[7] Bröcker B. How has COVID-19 impacted the travelling exhibition industry? Vastari, 2020. https://blog.vastari.com/covid-19-touring-exhibitions-impact/ [Accessed on 2020, 23 September]

[8] Hendrix G. The unsung business of travelling Museum exhibitions. The startup. 2019. https://medium.com/swlh/the-unsung-world-of-traveling-museum-exhibitions9a30d033ff2d [Accessed on 2020, 23 September]

[9] Sustainable Development Goals https://www.un.org/sustainabledevelopment/

[10] ULSF, 1990. Association of University Leader for a Sustainable Future http://www.ulsf.org (accessed 10.05.2021.).

[11] AASHE. The Association for the Advancement of Sustainability in Higher Education. Available at: http://www.aashe.org (accessed on 10.05.2021.).

[12] Grindsted T. S. and Holm T. Thematic development of declarations on sustainability in higher education, Environ. Econ., 3 (1), 2012, pp. 32-40

[13] Kloepffer W. Life cycle sustainability assessment of products (with comments by Helias A. Udo de Haes, p. 95). Int J Life Cycle Assess, 2008, 13(2), 89-95.

[14] UNEP/SETAC (2009) Guidelines for Social Life Cycle Assessment of Products. United Nations Environment Programme, Paris.

[15] Mapama (2018) Spain Government. [Online] www.miteco.gob.es/es/cambioclimatico/temas/mitigacion-politicas-y-medidas/factores_emision_tcm30-446710.pdf

[16] Díez O. (2019) Estudio de la sostenibilidad aplicada al diseño de una exposición itinerante. Final Degree Project. University of Zaragoza. 